\title{
Dietary intake and the dynamics of stress, hypertension and obesity in a peri- urban community in Accra
}

\author{
Husein Mohammed ${ }^{1,3}$, Shibani Ghosh ${ }^{2,3}$, Fred Vuvor ${ }^{1}$, Seth Mensah-Armah ${ }^{1,5}$, Matilda Steiner- \\ Asiedu ${ }^{1}$ \\ ${ }^{1}$ Department of Nutrition and Food Science, University of Ghana, Accra, Ghana ${ }^{2}$ Nevin Scrimshaw Interna- \\ tional Nutrition Foundation, Boston, USA ${ }^{3}$ Friedman School of Nutrition Science and Policy, Tufts Universi- \\ ty, Boston, USA ${ }^{4}$ School of Dietetics and Human Nutrition, McGill University, Canada ${ }^{5}$ Department of Food \\ and Nutrition, Iowa State University, Iowa, USA.
}

DOI: $h$ ttp://dx.doi.org/10.4314/gmj.v50i1.3

Corresponding author: Mr. Husein Mohammed_ E-mail: huseinmohammed@gmail.com

Conflict of interest: None declared

\section{SUMMARY}

Objectives: This study intends to investigate the association between dietary intake, stress and prevalence of chronic diseases.

Design and Setting: The study was a cross-sectional design conducted in two poor peri-urban communities in Accra.

Participants and outcome measures: A total of 90 households each with a male and female between the ages of 18 and 45 years were sampled, and their socio-demographic status, anthropometric measurement and fasting blood sugar were assessed. Blood pressure was measured and chronic stress/ anxiety was determined using the trait and state inventory (T-stai) questionnaire. Three days repeated 24-hour dietary recall was also done. Analysis of variance and linear regression analysis were used in data analysis.

Results: About $28 \%$ of the subjects were hypertensive and $55.5 \%$ had high chronic stress. Hypertension was higher in males (32.2\%) than females (24.4\%) ( $\mathrm{p}=.023)$ whiles stress was higher in females $(60.9 \%)$ than males $(50.0 \%)$ $(\mathrm{p}=.017)$. Hypertensive subjects recorded higher stress $(51.02 \%)$ and hypertension was more prevalent in subjects with high stress $(32.89 \%)$ especially in females $(57.14 \%, \mathrm{p}=.036)$. Hypertension increased with mean age whiles stress decreased with mean age. Hypertensive subjects recorded a significantly higher BMI and sodium intake whiles high stress individuals recorded a lower animal protein but a higher cereal protein intake $(\mathrm{p}<.05)$. Chronic stress was associated with intake of low animal protein and high cereal protein. Increased dietary diversity score was associated with decreased obesity prevalence $(\mathrm{p}<.05)$.

Conclusion: Hypertension, chronic stress, and obesity were linked, and affected by dietary sodium, animal protein, and dietary diversity of subjects respectively.

Keywords: Stress, hypertension, obesity, dietary intake

\section{INTRODUCTION}

Hypertension is defined as having blood pressure greater than or equal to $140 / 90 \mathrm{~mm} \mathrm{Hg}$, or currently undergoing anti-hypertensive treatment. ${ }^{1}$ Hypertension is now being widely reported in Africa and is the most common cause of cardiovascular disease on the continent. ${ }^{2}$ It is also a major factor in the high mortality of adults in subSaharan Africa. ${ }^{3}$ In Ghana, hypertensive renal disease is a common complication in both Kumasi and Accra. ${ }^{4}$

Dietary intake has been associated with increase or decrease prevalence of hypertension. Excessive consumption of sodium in diet, alcohol, saturated fatty acids and cholesterol have been associated with increased risk of developing hypertension, while high intake of potassium, calcium, magnesium and polyunsaturated fatty ac- ids rich foods have been associated with decrease in occurrence of hypertension and its related cardiovascular diseases in populations. ${ }^{5}$

Williams ${ }^{6}$ noted that the adaptive response to stress prepares individuals for fight or flight mechanism, but stress due to current lifestyles negatively impacts the response. This may result in reduced immune function and the emergence of diseases such as coronary heart disease, cancer, diabetes and hypertension. Stress also initiates the release of aldosterone, a corticosteroid that causes renal sodium retention, and vasopressin (antidiuretic hormone), which stimulates renal tubular water resorption thereby increasing blood volume and subsequently blood pressure. ${ }^{5}$ 
Chronic mental stress or high basal levels of stress hormones contribute to the development of peripheral disease $^{7}$ and clinical anxiety. ${ }^{8}$ However, in coping with mental stress, Fernstrom ${ }^{9}$ showed the importance of dietary essential amino acids. Recent studies have indicated that the essential amino acid L-lysine (Lys) reduces anxiety ${ }^{10}$ and normalizes stress-induced hormonal responses in healthy subjects with relatively high perceived anxiety. ${ }^{11}$ Animal foods on an average contain $85 \mathrm{mg}$ lysine per gram protein. In contrast to animal foods, cereals are not a good source of lysine and contain only $30 \mathrm{mg} / \mathrm{g}$ protein. ${ }^{12}$

The relationship between hypertension and dietary intake has been extensively documented but that of hypertension and stress is a vicious cycle. Understanding of the causal path of the cycle is a key to managing hypertension. It is against this background that this study was postulated.

\section{METHODS}

\section{Research design, setting and population}

This study is part of the baseline study of a supplementation trial conducted in two peri-urban communities in Accra. These communities were chosen because they have nucleated settlement, were densely populated, with mostly low socio-economic status and had poor social amenities, making them highly prone to stress and poor nutrition and hence hypertension.

\section{Sampling and Ethics}

Using a point estimate of 0.5 , allowable error of $7 \%$, at $95 \%$ confidence interval, a sample size of 194 was obtained. To ensure participation of the entire community, a house-to-house recruitment was done, and households who qualified and agreed to participate in the study were recruited and coded. Study participants were then randomly selected from those recruited. The study was thoroughly explained to the participants and those who signed the consent forms were selected for the study. A total of 90 households consisting of a man and woman (totalling 180 subjects), between the ages of 18 to 45 years, who have lived in the community for at least one year were recruited into the study. Selected subjects were also free from any physical and mental disabilities. The study protocol was reviewed and approved by Internal Review Board of the University of Ghana. Reconnaissance meetings were held with the chiefs and leaders of the communities and appropriate permission was provided before the commencement of the project.

\section{Data collection}

Socio-demographic information was collected using standardized questionnaire. Anthropometric measure- ments (height, weight and skinfold measurements), and 3-day repeated 24-hours dietary recall (two week days and one weekend to help get the subjects typical day's meal) were taken with the help of food models. The foods were converted into nutrients using the Ghana food composition table and USDA food composition table. ${ }^{13}$ Blood pressure was taken using sphygmomanometer at rest using standard procedure. ${ }^{14}$ Chronic anxiety was assessed using a local language translated and back translated (standardized) version of trait-state inventory (t-STAI) questionnaire. An inventory composed of 20 items for assessing chronic anxiety. ${ }^{15}$ Each item has a score of 1 to 4 , and the higher the cumulated score of a subject the higher the anxiety. A time difference of at least one week was allowed between obtaining tSTAI responses and blood pressure data collection. ${ }^{10}$

\section{Ethical Approval}

The Noguchi Memorial Institute for Medical Research Institutional Review Board approved the study. Consent forms were signed by all individuals who agreed to participate in the study after an explanation of the project in their local language.

\section{Data Analysis}

Data was entered in MS Access and data analysis was done using MS Excel spread sheet and SPSS. USDA data base ${ }^{13}$ was used in addition to the Ghanaian food composition tables, for detailed nutrient analysis including fatty acid breakdown and amino acid profile of the diet. Frequency distribution, chi-spare analysis, and linear regression analysis was used in data analysis. ANOVA and ANCOVA was used to control confounders during analysis.

\section{RESULTS}

Most of the respondents were between 18 to 38 years (71\%). The mean age (standard deviation) for the population was 33(7) years whiles, that of males was 33(8) years and females was 32(7) years. Majority of the subjects were in the low socioeconomic class. Majority of the male subjects were drivers $(15.6 \%)$ and masons $(16.7 \%)$; whiles most of the females were traders $(60 \%)$.

In general, there was inadequate intake of calcium ( $27.20 \%$ of RDA) and potassium ( $45.17 \%$ of RDA), and excess intake of sodium (197.88\% of RDA), especially in male subjects $(219.68 \%$ of RDA). Among all subjects, mean dietary intake of calories, (less than $65 \%$ of Average Energy Requirement or AER), were below their recommended requirement. Additionally, male intake of fibre (58.3\% of RDA) and female intake of iron $(51.5 \%$ of RDA) were low. 
Table 1 Distribution of malnutrition, hypertension and stress in study community

\begin{tabular}{lll}
\hline Indicator & Categories & N (\%) \\
\hline Malnutrition & Underweight & $8(4.5)$ \\
& Normal & $107(60.1)$ \\
& Overweight & $38(21.3)$ \\
& Obese & $25(14.0)$ \\
Blood pressure & Normal & $62(35.2)$ \\
& Pre-hypertensive & $64(36.4)$ \\
Stress (Chronic) & Hypertensive & $50(28.4)$ \\
& Normal & $77(44.5)$ \\
& High & $96(55.5)$ \\
\hline NB: Only 1(2\%) hypertensive subject knew of the status
\end{tabular}

About $28.4 \%$ of the participants were hypertensive and a further $36.4 \%$ of them were pre-hypertensive (table 1). Most of the hypertensive subjects (98\%) did not know their condition and hence were not under any form of treatment. Hypertension was higher among males $(32.2 \%)$ than in females $(24.4 \%)$. In total, hypertensive and pre-hypertensive subjects combined, make up $70 \%$ of males and $59.3 \%$ of female subjects in the study community. Overweight/obesity was also high, with $21.3 \%$ of the population being overweight and 14\% obese. Obesity was more endemic in females $(26.1 \%)$, with a $53.4 \%$ combined prevalence of overweight and obesity (Figure 1).

Hypertensive subjects had significantly higher mean sodium intake than normal subjects $(\mathrm{p}=.026)$. They recorded over $200 \%$ higher intake of sodium than the recommended dietary allowance. Male hypertensive subjects also had higher sodium intake than their normal counterparts $(p=.013)$, this was however not seen in female subjects $(p=.997)$. Body mass index (BMI) was much higher in hypertensive and pre-hypertensive subjects compared to normal subjects $(\mathrm{p}=.045)$.

More subjects had higher chronic stress (55.5\%) than the median stress levels of the participants (Table 1). In female $(60.9 \%)$ subjects recorded a significantly higher chronic stress (anxiety) state than male subjects (50\%) $(\mathrm{p}=.017)$. Mean stress levels increased with age group category, peaking in the middle age group (28-39years) and then dropping in subjects above 39years ( $\mathrm{p}=.036$ ).

Among female hypertensive subjects, high stress was significantly more prevalent $(57.14 \%)$ as compared with non-hypertensive female subjects $(33.87 \%)(\mathrm{p}=.036)$. This was however not seen in males.
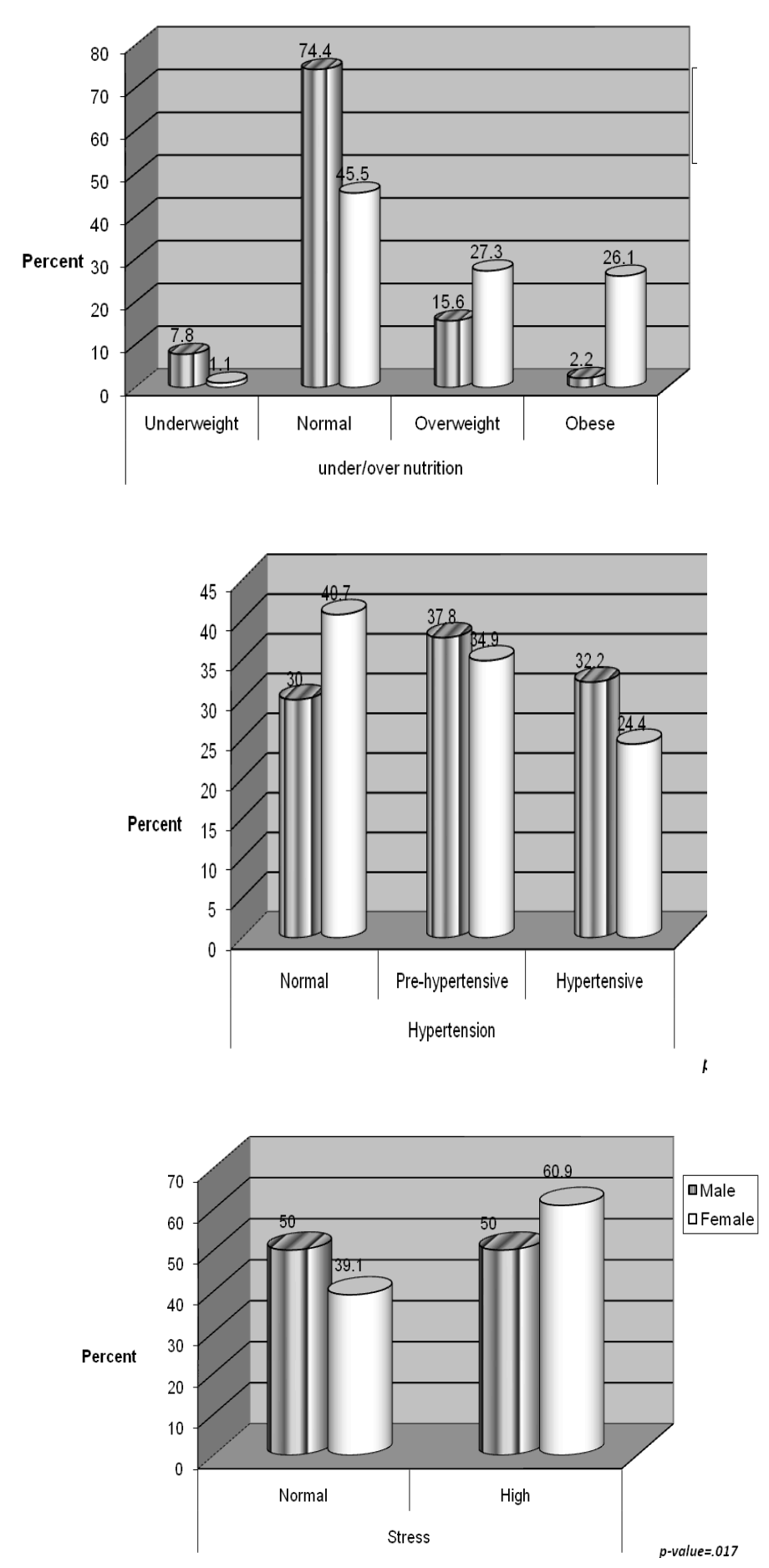

Figure. 1 Distribution of malnutrition, hypertension and stress among male and female subjects 


\section{Original Article}

Table 2 Factors associated with body mass index in study subjects

\begin{tabular}{|c|c|c|c|c|}
\hline $\begin{array}{l}\text { Dependent } \\
\text { variable }\end{array}$ & $\mathbf{R}^{2}$ & Predictors & Beta & $\begin{array}{l}\text { p- } \\
\text { value }\end{array}$ \\
\hline \multirow[t]{4}{*}{ Hypertension } & ,087 & Sodium (mg) & .167 & .035 \\
\hline & & lysine in $\mathrm{mg} / \mathrm{g}$ protein & -.180 & .015 \\
\hline & & BMI & .214 & .008 \\
\hline & & Sex & -.156 & .072 \\
\hline \multirow[t]{8}{*}{ BMI } & .474 & Age & .195 & .001 \\
\hline & & Lysine $\%$ RDA met & -.736 & .000 \\
\hline & & Hypertensive description & .115 & .045 \\
\hline & & kcal4 & .531 & .000 \\
\hline & & Sex & .515 & .000 \\
\hline & & $\begin{array}{l}\text { Protein (\%Energy Contribu- } \\
\text { tion) }\end{array}$ & .278 & .000 \\
\hline & & $\begin{array}{l}\text { Carbohydrate (\%Energy Con- } \\
\text { tribution) }\end{array}$ & -.163 & .016 \\
\hline & & $\begin{array}{l}\begin{array}{l}\text { Dietary } \\
\text { (DDS) }\end{array} \\
\text { Diversity }\end{array}$ & -.133 & .029 \\
\hline
\end{tabular}

There was a positive association between hypertension with sodium intake $(\mathrm{p}<0.05)$ however negative association existed between hypertension and lysine intake per gram protein consumed (OR(CI): 1.06 (1.0 to 1.1), $\mathrm{p}<.05)$. BMI was also associated with hypertension (OR(CI): 1.0 (0.9 to 1.0$), \mathrm{p}<.05)$. The percent RDA met for dietary lysine, carbohydrate contribution to dietary energy and dietary diversity score of subjects had a negative association with body mass index $(\mathrm{p}<.05)$ (table 2).

Males with higher anxiety recorded a significantly lower mean age $(p=.035)$, lower percentage body fat $(\mathrm{p}=.029)$ and their diet had lower animal protein $(\mathrm{p}=.003)$ content than normal males. They however recorded a significantly higher cereal protein $(p=.021)$ making up their diet. This was not seen in females with high chronic stress levels.

\section{DISCUSSION}

It was observed that generally the prevalence of overweight/obesity was high, with $21.3 \%$ of the population overweight and $14 \%$ obese. Prevalence of overweight and obesity together was about $35 \%$ of the study subjects. Obesity in the subjects studied was much higher than that recorded $(5.5 \%)$ by Biritwum ${ }^{16}$ but same as that recorded by Amoah. ${ }^{17}$ This prevalence rate confirms the literature explanation of an increasing prevalence of obesity in developing countries. About 28.4\% of the study populations were hypertensive with a further $36.4 \%$ of them also being pre-hypertensive. The high levels of hypertension and pre-hypertension in this study confirms report by Amoah, ${ }^{1}$ which recorded a $28.4 \%$ crude prevalence of hypertension in Accra, with only $34 \%$ of hypertensive subjects were aware of their status, $18 \%$ were treated and only $4 \%$ were controlled.
However, in this study, over $98 \%$ of hypertensive subjects in study population did not know their diseased condition and hence were not under any form of treatment. Overweight/obesity is a significant risk of hypertension in individuals and it has been documented that the risk of developing elevated blood pressure is two to six times higher in overweight than in normal-weight persons. ${ }^{5}$ It is therefore not surprising that a similar trend was found in this study were hypertension was associated with overweight/obesity $(\mathrm{p}<0.05)$.

Hypertension was higher among males than in females. This was expected as males had a higher dietary sodium and alcohol consumption and this puts them at a greater risk of developing hypertension. Mahan and EscottStamp ${ }^{5}$ reported that, pre-hypertensive individuals have a higher future risk of developing hypertension than normal subjects. In total, hypertensive and prehypertensive subjects make up $70 \%$ of males and $59.3 \%$ of female subjects in the study population. This also shows a future worsening of hypertension prevalence in both groups. It may also be due to the higher than normal level of sodium and low level of potassium and calcium in their diet. In the Dietary Approach to Stop Hypertension (DASH) sodium study, a reduction in sodium intake caused stepwise decreases in blood pressure. ${ }^{18}$ Also because of its role in muscle function and because it is not produced in the body, dietary calcium is required in sufficient daily quantities to achieve and maintain appropriate blood pressure levels through optimal regulation of vascular resistance. ${ }^{19}$ Population studies have also shown an inverse relation of potassium intake to blood pressure, the prevalence of hypertension, or the risk of stroke. ${ }^{5,20}$

It was also observed that hypertension prevalence was higher in individuals with high chronic stress than in normal individuals, especially in female subjects. This indicates a higher risk of hypertension among individuals with higher chronic stress/anxiety than those with lower or normal stress/anxiety. Lekh ${ }^{21}$ showed a significant decrease in both anxiety and blood pressure in hypertensive subjects after long term relaxation exercise. Mahan and Escott-Stamp ${ }^{5}$ reported that stress initiates the release of aldosterone, a corticosteroid that causes renal sodium retention, and vasopressin (antidiuretic hormone), which stimulates renal tubular water resorption thereby increasing blood volume and subsequently blood pressure.

Lower dietary animal protein and higher cereal protein in high stress male subjects could be partly attributed to decreased essential amino acids with 1-lysine being the most limiting amino acid. 
Animal protein contains higher essential amino acids such as 1-lysine amino acid, whiles cereal protein contains lower l-lysine amino acid.

Essential amino acids are important is stress response, ${ }^{5}$ most of which are more available in animal protein and least available in cereal. ${ }^{12}$ Decreased levels of essential amino acids may also result in decreased synthesis and increased catabolism which may be responsible for the lower body fat stores in high stressed male subjects. ${ }^{5}$

High protein consumption was associated with increased BMI in the study subjects. This could be because common protein foods (such as beans and meat) in the community are eaten with lots of fat and/oil (fried so increased calories). There was however a negative association between BMI and lysine percent RDA met, carbohydrate contribution to dietary energy and dietary diversity score of subjects. Increased fibre in more diversified and carbohydrate foods, compared to fatty or oily protein foods may account for this.

\section{CONCLUSION}

Hypertension prevalence in the study area was very high, more endemic in males than in females, and was associated with increased BMI, chronic stress or anxiety and dietary sodium intake. It was recommended that sodium restriction, stress management, management of overweight/obesity be made an integral part of hypertension prevention programs and management. Routine screening of hypertension, especially in peri-urban communities is also highly recommended in public health campaigns.

\section{REFERENCES}

1. Amoah AGB. Hypertension in Ghana: a crosssectional community prevalence study in greater Accra. Ethn Dis. 2003;13(3):310-315.

2. Cooper RS and Rotimi C. Establishing the epidemiologic basis for prevention of cardiovascular diseases in Africa. Ethn Dis. 1993;3: 13-22.

3. World Health Organization. The World Health Report: Reducing risks, promoting healthy life. Geneva, Switzerland: WHO; 2002.

4. Plange-Rhule J, Phillips R, Acheampong JW, Saggar-Malik AK, Cappuccio FP, Eastwood JB. Hypertension and renal failure in Kumasi, Ghana. $J$ Hum Hypertens. 1999;13: 37-40.

5. Mahan LK and Escott-Stamp S. Krause's Food and Nutrition Therapy. 12th ed. Saunders and Elsevier, USA. 2008; Pp 417-423, 1022

6. Williams SR. Nutrition and diet Therapy. $7^{\text {th }}$ ed. Mosby Year Book, Inc. Westline Indusrial drive. St. Luis USA. 1993;Pp 431-450
7. Schulz KH and Gold S. Psychological stress, immune function and disease evelopment. The psychoneuroimmunologic perspective. Bundesgesundheitsblatt Gesundheitsforschung Gesundheitsschutz. 2006;49:759-772

8. Muller JE, Koen L and Stein DJ. Anxiety and medical disorders. Curr Psychiatry Rep. 2005;7:245251

9. Fernstrom JD. Can nutrient supplements modify brain function? Am J Clin Nutr. 2000;71, 1669S1673S.

10. Smriga M, Ghosh S, Mouneimne Y, Pellett PL and Scrimshaw NS. Lysine fortification reduces anxiety and lesens stress in family members in economically weak communities in Northwest Syria. Proc Natl Acad Sci U S A. 2004; 101:8285-8288.

11. Daniela J, Aikaterini M, Miro S, Yasushi M, \& Roman D. Subchronic treatment with amino acid mixture of L-lysine and L-arginine modifies neuroendocrine activation during psychosocial stress in subjects with high trait anxiety. Nutr Neurosci. 2005;8(3), 155-160.

12. Pellett PL. World essential amino acid supply with special attention to South-East Asia. Food Nutr Bull. 1996;17(3) 204-234.

13. U.S. Department of Agriculture ARS. USDA National Nutrient Database for Standard Reference, Release 18. Nutrient Data Laboratory. 2005 [updated 2005; cited 2010 January 27, 2010]; Available from: http://www.nal.usda.gov/fnic/foodcomp/Data/.

14. Thomas GP, John EH, Lawrence JA, Bonita EF, John G, Martha NH, Daniel WJ, Theodore K, Sheldon GS, and Edward JR. Recommendations for Blood Pressure Measurement in Humans and Experimental Animals: Part 1: Blood Pressure Measurement in Humans: A Statement for Professionals From the Subcommittee of Professional and Public Education of the American Heart Association Council on High Blood Pressure Research. Hypertension 2005; 45:142-161.

15. Hishinuma ES, Miyamoto RH, Nishimura ST, Goebert DA, Yuen NY, Makini GK, Andrade NN, Johnson RC and Carlton BS. Prediction of anxiety disorders using the State-Trait Anxiety Inventory for multi-ethnic adolescents. J Anxiety Disord. 2001;15:511-533.

16. Biritwum RB, Gyapong J and Mensah G. The Epidemiology of Obesity in Ghana. Ghana Med J. 2005;39(3): 82-85

17. Amoah A.G. Sociodemographic variations in obesity among Ghanaian adults. Public Health Nutr. 2003;6: 751-757

18. Appel LJ, Moore TJ, Obarzanek E, Vollmer WM, Svetkey LP, Sacks FM, Bray GA, Vogt TM, Cutlet 
JA, Windhauser MM, Lin PH, Karanja N. DASH Collaborative Research Group: A clinical trial of the effects of dietary patterns on blood pressure. $N$ Engl J Med. 1997;336:1117-1124.

19. McCarron DA and Reusser ME. Finding Consensus in the Dietary Calcium-Blood Pressure Debate. Published by the American College of Nutrition. $J$ Am Coll Nutr. 1999;18(5):398-405.
20. Whelton PK. Potassium and blood pressure In: Izzo JLJr, Black HR. $3^{\text {rd }}$ ed. Dallas: American Heart Association/Council of High Blood Pressure Research.USA. 2003; Pp 280-282.

21. Lekh RB. Long-Term Effect of Relaxation on Blood Pressure and Anxiety Levels of Essential Hypertensive Males: A Controlled Study. Psychosom Med. 1979;41(8):637-646 